\title{
The epic of San Benedetto del Tronto (I) ocean fishing
}

\author{
Serafino Angelini ${ }^{\mathrm{a},} *$ Michele Del Zompo $^{\mathrm{b}}$ \\ ${ }^{a}$ GeoSoul Italia Ltd., serafino.angelini@geosoul-italia.it \\ ${ }^{b}$ Master Mariner, freelance, delzompomichele7@gmail.com \\ * Corresponding author
}

Keywords: Thematic maps, Ocean fishing, exploration maps, navigation routes, fishing areas

Abstract:

Ocean fishing has had a profound impact on the economy of suitable locations, especially for those realities with an ancient tradition linked to fishing overlooking the Adriatic Sea.

After the devastation suffered during the Second World War and the slow subsequent recovery, starting from the second half of the 1950s, thanks to the insights of some young shipowners, the exploration of the West African coast began in order to carry out a series of fishing campaigns. Although there had been previous experiences always on the initiative of the San Benedetto marinery between the first and second world wars in the North Atlantic (Iceland, Greenland) up to the Canadian coasts, African fishing was the beginning of a flourishing activity that sent to work ships still far from current possibilities and equipment, practically in every part of the globe. The living conditions of the vessels' crew were terrible, they were subjected to inhuman efforts rewarded by earnings that at that time, in Italy, would have been unthinkable. Protagonists of that season, a generation of heroes who created a national and international market out of nothing that, at that time, had laughable numbers, because they were linked to local and coastal activities, apart from some insignificant exceptions in quantitative terms.

The maritime tradition of San Benedetto del Tronto was fundamental to develop through trial and error, often guided only by instinct, fishing systems suitable for all types of fishing and in all the seas of the world, also giving a great boost to the economy linked to fishing in other areas of Italy such as Lampedusa and Viareggio, localities still closely linked with the reality of San Benedetto del Tronto.

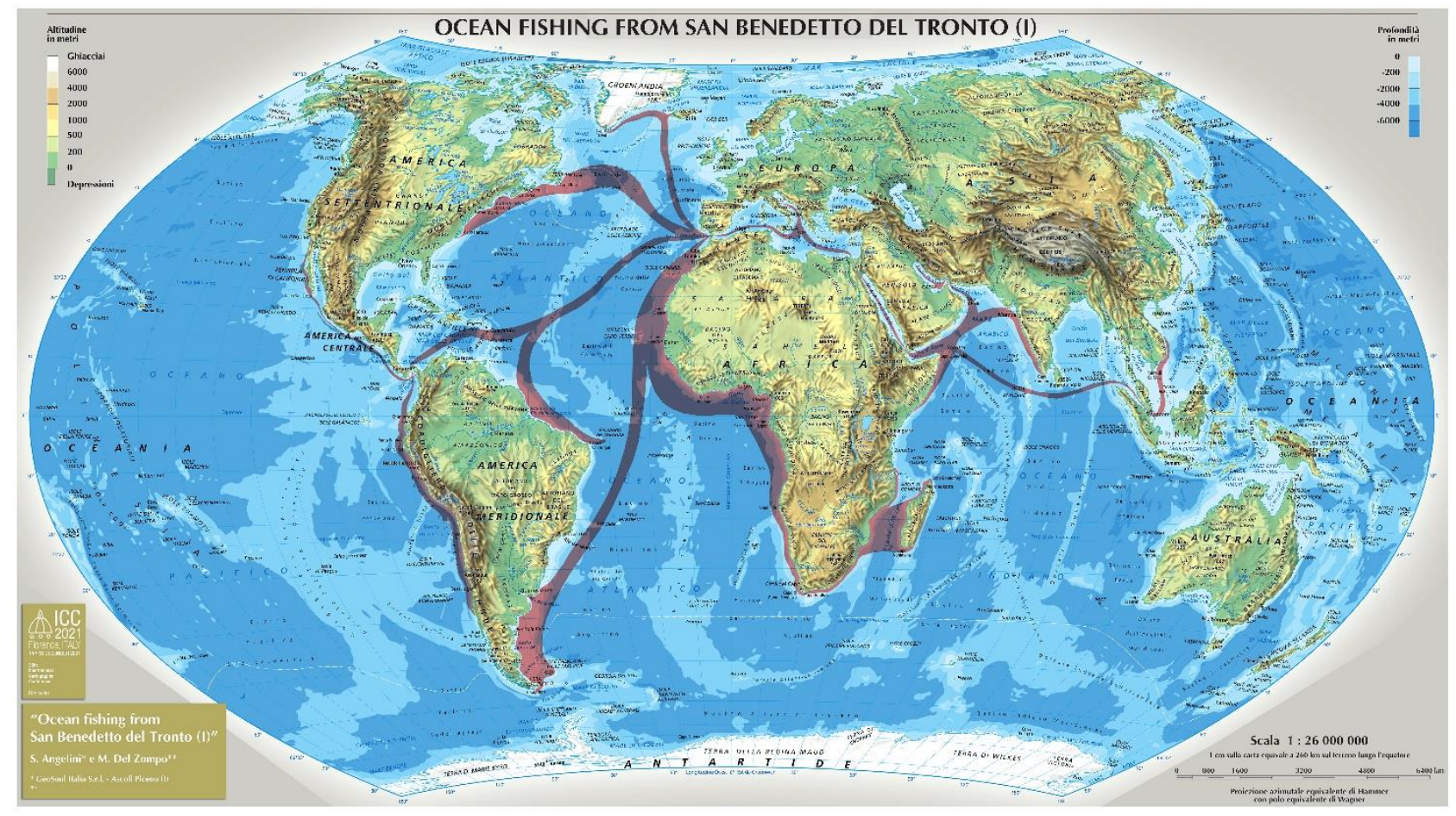

Figure 1. Map of ocean fishing grounds from San Benedetto del Tronto. 
Thanks to that series of campaigns, the city of San Benedetto del Tronto experienced a real economic boom, coming to build from scratch the first city for tourist accommodation in the Marche Region and one of the first in the entire Adriatic. With the sacrifice of courageous men and tireless workers, an entire society achieved in the space of twenty years an otherwise impossible comfort, developing locally industries for the processing and marketing of fish, shipbuilding, but also hotels, commercial activities and not least by having the possibility of having their children study.

The purpose of this work is the creation of a relational cartographic database within which to store the information relating to the campaigns carried out by the Sambenedettese navy around the seas of the world and to reconstruct the historical memory of the operations through grey literature, logbooks, nautical charts, direct experience of the protagonists and the cartographic representation of a synthesis product on a global scale (1:26,000,000), with an object on a more detailed scale for the Mediterranean basin, where the main landings of the San Benedetto del Tronto fishing fleet are indicated.

Through the sources cited, it was possible to reconstruct the routes traveled and the fishing areas identified. The main classification took place through the starting period of the campaign and, where possible, the main fishing areas were reconstructed, what type of product was supplied to the Italian and European market in general. This relational database will be useful for storing the thousands of documents that probably still exist today but too often not guarded with due care.

Thanks to Mr. Nazzareno Torquati and Mr. Mariano Nico for their useful contribute, and a special mention for Mr. Silvio "Cocisse" Angelini, for his guide.

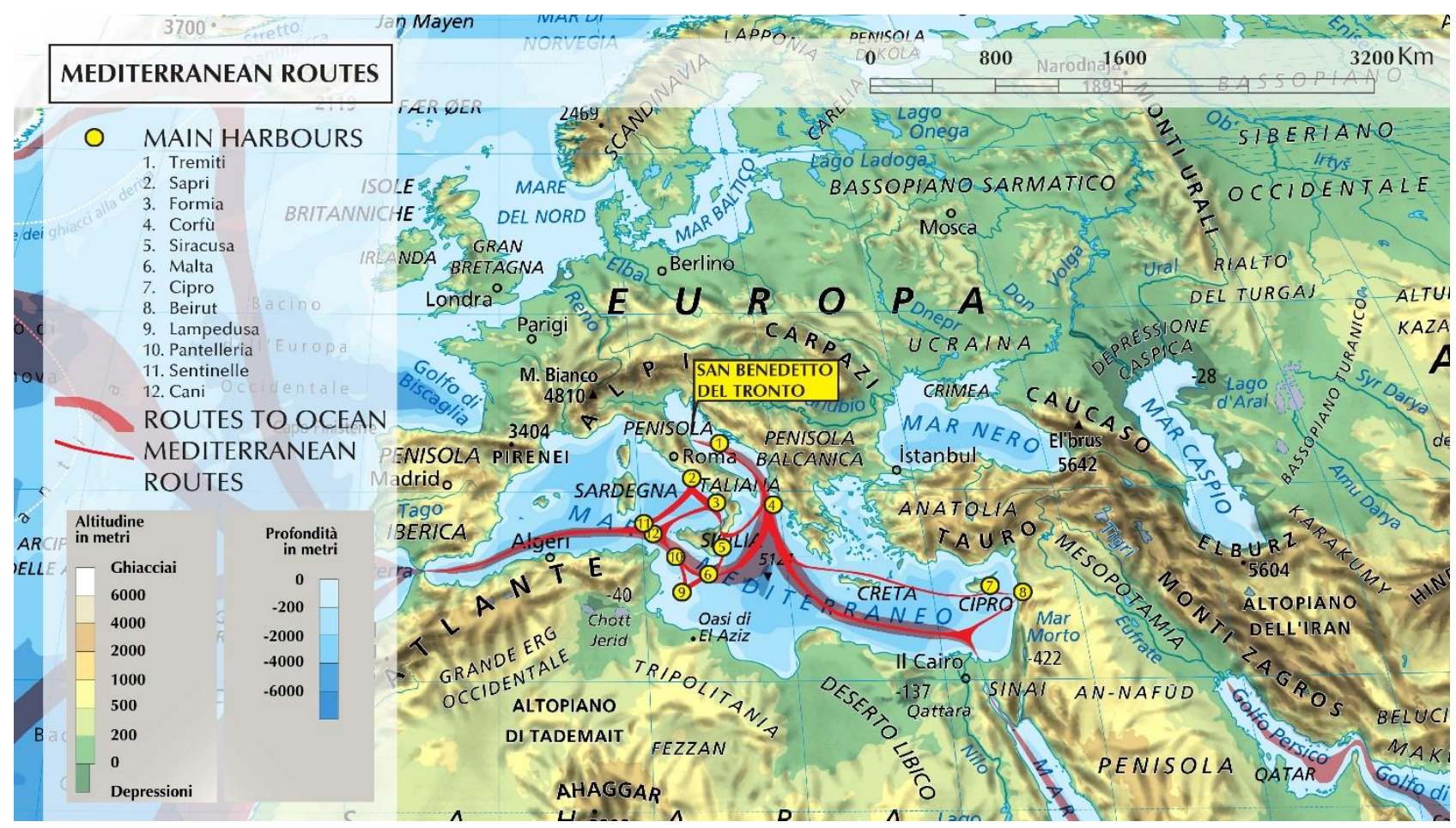

Figure 2. Map of main routes whitin Mediterranean sea 